\title{
Oligometastatic Disease in Colorectal Cancer - How to Proceed?
}

\author{
Felix Aigner Johann Pratschke Moritz Schmelzle \\ Department of Surgery, Charité - Universitätsmedizin Berlin, Campus Charité Mitte, Campus Virchow-Klinikum, Berlin, Germany
}

\section{Keywords}

Synchronous · Liver-first · Resectability ·

Oligometastatic $\cdot$ Multimodal

\section{Summary}

Background: Oligometastatic disease in colorectal cancer may affect the liver, lung, and peritoneum. This review mainly focuses on colorectal liver metastases (CRLM) and highlights recommendations and therapeutic strategies drawn from the current literature and consensus conferences. The following data address a paradigm shift in surgical approaches to CRLM, pushing the limits of multimodal treatment concepts. Methods: A systematic review of the relevant literature on multimodal treatment strategies for synchronous and metachronous CRLM is presented. Results: The choice of treatment strategy depends on the clinical scenario; however, perioperative chemotherapy and the liver-first concept in synchronous CRLM are favored with subsequent partial extended liver resection with or without various augmentation techniques for liver surgery. Conclusion: Surgical strategies should be strongly defined with regard to an adequate liver remnant. All patients with synchronous CRLM should be evaluated by a multidisciplinary team.

(C) 2017 S. Karger GmbH, Freiburg

\section{Introduction}

Colorectal cancer (CRC) is the second most frequent cancer and represents $13 \%$ of all cancer cases in Europe. Approximately one fourth of all patients show metastases at the initial diagnosis, and almost $50 \%$ of CRC patients will develop metastases. The CRC-related 5-year survival rate approaches $60 \%$ [1]. The primary sites of colorectal metastasis are the liver and lungs; however, peritoneal carcinomatosis may result from T4 CRC, especially in connection with tumor perforation.

Discrepancies exist in the definition of synchronous metastases in the literature, such as metastases detected at or before diagnosis or surgery of the primary tumor, or metastases detected up to 3-6 months. Also, in the absence of data from randomized controlled trials, no treatment algorithm can be provided to date [2]. A multidisciplinary approach for selecting the best treatment strategy is mandatory in metastatic CRC (mCRC).

The aim of this review is to offer recommendations as to how to proceed with oligometastatic disease in CRC.

\section{Prognosis}

The prognosis of $\mathrm{mCRC}$ deteriorates with the synchronicity of the metastases and is worse when metastases are detected at or 1 month before the diagnosis of the primary tumor versus up to 6 months or 6-12 months after diagnosis [2]. The 5-year survival after R0 resection of colorectal liver metastases (CRLM) has been reported to be $25-40 \%$ [3].

\section{Methods}

Recommendations within this review are derived from data from the current literature. A PubMed search was carried out with the following search terms: 'colorectal cancer', 'metastases', 'treatment', 'oligometastatic', 'consensus'.

\section{Results}

\section{Definition/Subgroups}

Patients with $\mathrm{mCRC}$ can be principally divided into four clinical groups according to treatment intention [1]:

\section{KARGER}

(c) 2017 S. Karger GmbH, Freiburg

Fax +497614520714
PD Dr. med. Felix Aigner 
(1) Patients suitable for resection of liver and/or lung metastases.

(2) Patients with metastatic disease potentially resectable with curative intent, but requiring downsizing with the most active 'induction' chemotherapy to enable secondary surgery.

(3) Patients with disseminated disease, technically never/unlikely resectable metastatic disease suitable for intermediate intensive treatment.

(4) Patients with clearly unresectable mCRC.

However, the outcome of patients with mCRC has remarkably improved over the last years with convincing survival rates [1].

\section{Diagnosis}

Routine CRC staging includes clinical examination, complete colonoscopy, histology of the primary tumor, computed tomography (CT) scans of the chest, abdomen and pelvis, magnetic resonance imaging (MRI) and endorectal ultrasound in rectal cancer, and tumor marker status (carcinoembryonic antigen (CEA)). Clinical examination with regard to intensive chemotherapy should include blood counts, liver and renal function tests, and CEA.

\section{Imaging Studies}

The best methods for staging CRLM are CT and MRI. The sensitivity of MRI can be enhanced using liver-specific contrast agents such as gadoxetic acid (Primovist ${ }^{\circledR} /$ Eovist $^{\circledR}$; Bayer HealthCare Pharmaceuticals, Whippany, NJ, USA) and gadobutrol (Gadovist ${ }^{\circledR}$; Bayer Shering Pharma, Berlin, Germany). A diagnostic bias, however, appears with the incidence of vanishing liver metastases after neoadjuvant treatment. Many studies that have described the phenomenon of vanishing liver metastases only used CT and intraoperative ultrasound (with only scarce evidence for perioperative detection of vanishing liver metastases even with contrast enhancement [4]) to assess the response to neoadjuvant systemic therapy. In up to $80 \%$ of resected regions in which vanishing liver metastases had been observed, viable tumor residuals were detected, and conservative management of radiologically disappeared liver metastases resulted in 19-74\% local recurrence, mostly within 2 years [5]. Hence, even liver metastases that disappear after neoadjuvant chemotherapy require an aggressive surgical approach, and restaging modalities should include at least a combination of CT and contrast-enhanced MRI.

Positron emission tomography (PET)-CT scans can be employed for the detection of extrahepatic metastatic or recurrent disease; however, studies have not demonstrated any beneficial effect on disease-free or overall survival through decision-changing regarding treatment management following PET-CT performance [3].

Regarding liver resection response based on size, morphological criteria of CRLM following RECIST and assessment of steatosis and signs of portal hypertension as well as evaluation of the predicted future liver remnant are key indicators of response that should be provided by the radiologist.

\section{Molecular Biology}

Synchronous and metachronous CRLM are still not distinguishable by biomarker studies; however, specific biomarkers such as epidermal growth factor receptor (EGFR, KRAS wild-type expression) mutations have been associated with worse disease-free and overall survival following CRLM resection $[2,6]$.

\section{Liver Resection - Strategy and Technical Aspects}

\section{Liver Surgery - General Aspects}

During the last decade, surgery has become an established part of multimodal therapy concepts in CRLM. Based on recent prospective data and multiple retrospective analyses, 5-year survival rates of $30-50 \%$ could be repeatedly demonstrated at experienced centers $[7,8]$. Importantly, survival rates after liver resection do not differ between patients undergoing surgery for synchronous or metachronous CRLM [8].

Consequently, surgery is recommended as first-line therapy for technically resectable CRLM in patients suitable for operation according to various national guidelines [3]. Patients with R0 resectable liver and lung metastases should be considered for primary surgery depending on their clinical status. This decision must be discussed and made within a multidisciplinary board. Symptomatic primary tumors (bleeding, obstruction, or perforation) must be considered for emergency surgery in most cases (except for bleeding) as the primary treatment concept. It should be kept in mind that resectability of liver metastases is not only defined by technical but also functional and oncological criteria. Technical resectability is dependent on the center and the surgeon [9], and is not limited by the number or size of the metatstases or bilobar involvement.

\section{Surgery in Multimodal Therapy Concepts}

Although survival data after liver resection for CRLM are promising, intra- and extrahepatic recurrence is evident in $50-70 \%$ of patients within 5 years of surgery [10]. Prognosis with regard to recurrent liver metastases can be preoperatively evaluated using scoring systems according to Fong et al. [11], Nordlinger et al. [12], and Rees et al. [7]. Even in patients with recurrent disease, surgery has risen to the forefront of promising treatment strategies as a vital part of multimodal therapy concepts in patients suffering from CRLM.

To date, the timing of liver resection and the management of the primary tumor in synchronous CRLM are still being debated. Some expert panel recommendations focus on neoadjuvant chemotherapy before surgery of the CRLM in patients with more than one poor prognostic factor (i.e. multiple CRLM, $>5 \mathrm{~cm}$ in diameter, lymph node-positive primary, and high tumor markers [11, 13]), even if the metastases are technically resectable [14]. Neoadjuvant chemotherapy before liver surgery addresses micrometastases and circulating tumor cells in order to reduce recurrent metastatic disease in resectable CRLM, and downsizes liver lesions with the aim of achieving resectability in initially unresectable CRLM. However, neoadjuvant treatment strategies with cytotoxic doublets (e.g. oxaliplatin- or irinotecan-based therapy) and targeted agents (e.g. bevacicumab or cetuximab) cause time-dependent liver dam- 
Fig. 1. Treatment algorithm for synchronous (i.e. at or $<6$ months after primary diagnosis) oligometastatic colonic liver metastases.

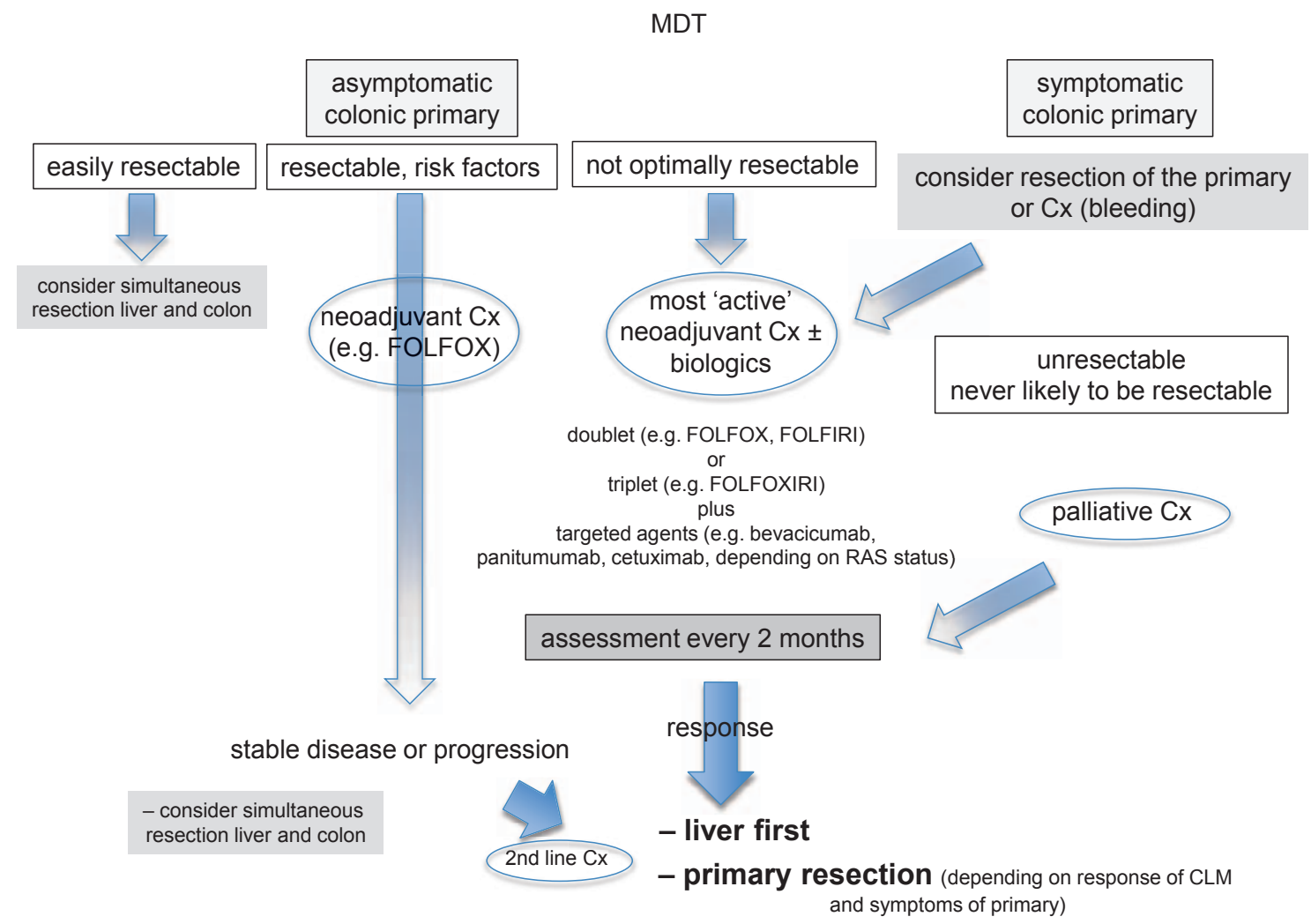

age due to vascular lesions (sinusoidal obstruction syndrome) following oxaliplatin-based chemotherapy and steatohepatitis with higher rates of infectious complications following irinotecan-based chemotherapy, resulting in increased 90-day mortality due to liver failure after surgery [15]. Therefore, the duration of preoperative chemotherapy should be limited to 3 months. Neoadjuvant chemotherapy, especially when adding targeted agents like anti-vascular endothelial growth factor antibodies with augmented chemotherapy-induced hepatic lesions and diminished regeneration after resection, should be stopped at least 6 weeks prior to surgery for bevacizumab and 3-4 weeks for 5-fluorouracil/leucovorin (5-FU/ LV) [14].

Figures 1 and 2 show possible clinical scenarios and treatment options for synchronous CRLM.

Whether CRLM should be treated by surgery combined with perioperative chemotherapy or surgery alone followed by palliative chemotherapy in unresectable recurrent disease is still controversial. In the recent EPOC trial, no difference was found in overall survival after addition of perioperative chemotherapy with FOLFOX4 (oxaliplatin, 5-FU, LV) compared with surgery alone for CRLM [16]. However, the previously observed benefit in progression-free survival with the addition of perioperative chemotherapy might indeed favor perioperative chemotherapy, although no change in survival was seen (EORTC new study [16]). As demonstrated in figures 1 and 2, doublet or triplet chemotherapy including oxaliplatin and irinotecan and targeted agents depending on RAS status are promising strategies which can increase the proportion of potentially resectable patients by approximately $30 \%$ [17].
Moreover, significant differences in overall survival exist favoring patients with left-sided tumors, who had a markedly better prognosis than those with right-sided tumors within the RAS wildtype population [18].

Proposed benefits of neoadjuvant chemotherapy include a preoperative selection of biologically aggressive metastases. According to a LiverMetSurvey Registry analysis of 12,465 patients, the overall survival of patients with disease progression after neoadjuvant chemotherapy followed by surgery is approximately $15 \%$ compared to $40-45 \%$ in patients with complete or partial response or stable disease after neoadjuvant chemotherapy followed by surgery [19]. Of note, patients with disease progression should not generally be excluded from liver resection; however, radiological response to chemotherapy in combination with the evaluation of other biological prognostic factors, e.g. size and number of metastases or CEA levels [7], might help to individualize therapy concepts.

\section{Unresectable Liver Metastases}

Irrespective of the question of whether perioperative chemotherapy should be favored or not, patients with technically unresectable CRLM should be scheduled for conversion chemotherapy. Bischof et al. [20] reported successful down-sizing leading to secondary resectability in up to $20 \%$ of initially unresectable CRLM. Remarkably, all patients included in the phase III FIRE-3 study considered initially unresectable and scheduled for intensive systemic treatment of CRLM were recently re-evaluated by an expert panel of experienced hepatobiliary surgeons. This review (manu- 


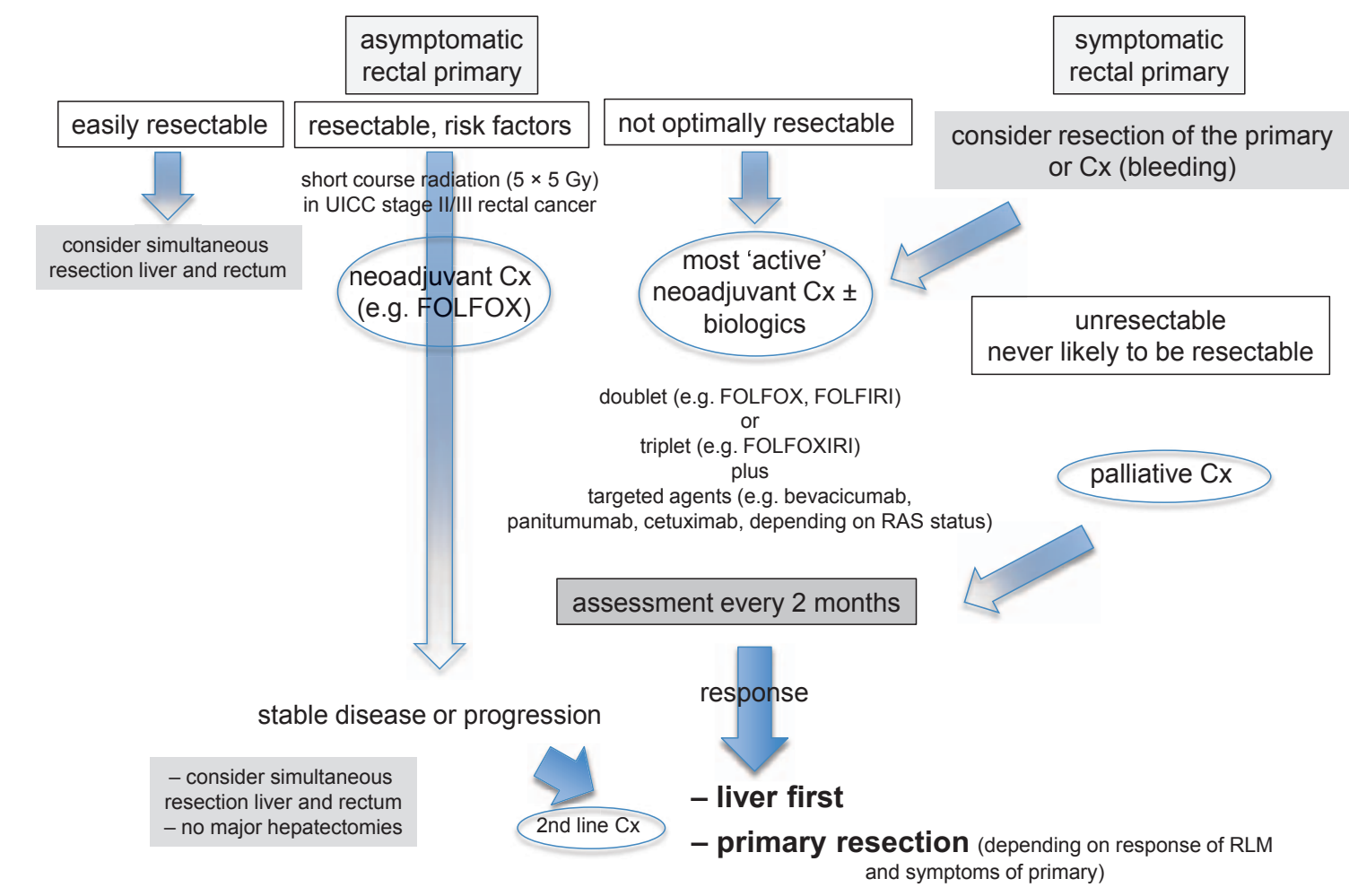

Fig. 2. Treatment algorithm for synchronous (i.e. at or $<6$ months after primary diagnosis) oligometastatic rectal liver metastases. and symptoms of primary) script submission pending) indicates that the proportion of secondarily resectable patients can be dramatically increased to up to $50 \%$ in experienced hepatobiliary centers.

\section{Disappearing Liver Metastases}

Metastases showing complete response after chemotherapy might be characterized by a favorable biology. It has been debated whether patients with complete radiological response should undergo liver resection or should be scheduled for watch and wait procedures. It is important to note that radiological response of CRLM does not predict the pathological response of regressive tumor nodules. According to retrospective data by Bischof et al. [20] and van Vledder et al. [21], patients with disappearing liver metastases undergoing resection of all original tumor sites are characterized by significantly increased overall survival rates when compared to patients where disappearing liver metastases were left in situ. Consequently, in the case of complete response to chemotherapy, sites of initial tumor growth should be addressed surgically. Whether the use of marking techniques with clips or other dense particles, as proposed by Zalinski et al. [22], should be standard procedure in patients before preoperative chemotherapy, is controversial. According to our own experience, identification of initial sites by pre-chemotherapy staging CT together with intraoperative contrast-enhanced ultrasound enables the detection of sites of tumor growth in such patients.

\section{Combination Therapy with Surgery and Ablation}

According to a recent meta-analysis, liver resection of singular CRLM appears to be associated with superior survival rates when compared to radiofrequency ablation (RFA), with no differences in postoperative morbidity and mortality. However, patients with unresectable CRLM following chemotherapy might indeed be evaluated for individual therapy concepts, e.g. combined resection/ablation approaches using additional intra- or postoperative RFA or brachytherapy. Given the low evidence of retrospective single center analyses per se, strong recommendations for combined resection/ablation approaches cannot be given so far [23]. However, according to convincing experience in early hepatocellular carcinoma [24], small but unresectable metastases are being increasingly addressed by ablation in experienced hepatobiliary centers if the predominant number of metastases can be technically addressed by resection. Low evidence even suggests that individual therapy concepts favoring surgery might be indicated in selected patients with resectable CRLM and local peritoneal spread [25].

\section{Strategies in Synchronous Liver Metastases}

Based on historical data, combined resection of the primary colorectal tumor together with major liver resection of synchronous CRLM should be avoided due to increased morbidity and perioperative mortality rates. This dogma has led to novel strategical approaches, e.g. the liver-first concept. Resection of CRLM 4-6 weeks before colorectal surgery for the primary tumor can be performed with morbidity and mortality rates comparable to established primary-first paradigms [26]. The liver-first concept has immense advantages and should be favored in cases where progression of CRLM is suspected after colorectal surgery, resulting in presumed unresectability, e.g. evident in large metastases or metas- 
Table 1. Resection and local ablative treatment options for CRLM

\begin{tabular}{l}
\hline Resection methods \\
Minor resections \\
Atypical liver resection \\
Local excision \\
Left lateral segmentectomy \\
Major resections \\
Right/left hepatectomy \\
Trisectionectomy \\
ALPPS procedure \\
\hline Local ablation techniques \\
Radiofrequency ablation \\
Microwave ablation \\
Laser-induced interstitial thermal therapy (LITT) \\
Internal radiation therapy \\
Afterloading technique \\
\hline
\end{tabular}

tases close to large vessels or in patients at high risk of a delayed treatment course following colorectal surgery due to complications. Local control of the primary tumor (e.g. rectal cancer in the mid or lower third) without delaying neoadjuvant treatment of CRLM can be achieved by short-course radiation with subsequent induction chemotherapy using cytotoxic doublets/triplets and/or targeted agents.

\section{Liver Resection for Bilobar Metastases}

Patients with bilobar liver metastases have been considered not good candidates for liver resection in the past. Nowadays, it is well accepted that even patients with bilobar metastases might benefit from liver resection and should be evaluated for technical resectability. Different techniques and strategies have been established for bilobar liver metastases within the last years including two-stage approaches and techniques for liver augmentation.

Two-stage hepatectomy strategies are based on the natural capacity of the liver to regenerate after loss of liver volume. This phenomenon is called hypertrophy and can be induced before extended right hepatectomies by several techniques, e.g. portal vein embolization (PVE) or ligation (PVL) of the right-sided portal vein branches with or without transection of the liver parenchyma (associating liver partition with portal vein ligation for staged hepatectomies (ALPPS)) between the left lateral (segments 2 und 3) and left medial (segment 4) sector [27]. In the case of bilobar liver metastases, left lateral metastases are cleared in a first operation combined with PVE, PVL, or ALPPS, followed by an extended right liver resection 4-6 weeks or even earlier after 1-2 weeks (following ALPPS) after sufficient hypertrophy. Of note, neoadjuvant chemotherapy of $\leq 5$ cycles does not significantly increase the perioperative morbidity. However, evaluation of the functional liver capacity using liver function tests such as LiMAx [28] is essential for the safe performance of liver surgery, especially after chemotherapy.
Table 1 demonstrates the variety of resection or local ablative treatment options for CRLM.

\section{Minimally Invasive Liver Surgery}

Minimally invasive surgery has several benefits over conventional open surgery and has been established during the last years in the field of colorectal surgery and others. Several studies confirmed that laparoscopic surgery is a safe and radical approach with non-inferior oncological results compared to open colorectal surgery [29]. Possible approaches for laparoscopic liver resection were limited to non-anatomical resections or anatomical minor resections, e.g. bisegmentectomy, for many years. During the last years, techniques in laparoscopic liver resection have dramatically improved, allowing laparoscopic liver resections to be performed safely nowadays [30]. Even major liver surgery, e.g. (extended) hemihepatectomy, can be performed safely in experienced hepatobiliary centers on a routine basis. Even though randomized controlled trials comparing open with laparoscopic surgery for CRLM are still missing, recent meta-analyses have confirmed the wellknown clinical advantages of laparoscopic surgery in the treatment of CRLM (e.g. lower blood loss, shorter hospital stay, and lower local recurrence rates) with no significant differences in postoperative mortality, 5-year disease-free-survival, and overall survival [31]. One of the most common indications for laparoscopic liver resections is CRLM. From our point of view, conventional open hemihepatectomy should be limited to selected cases and is generally no longer indicated for resectable CRLM. Even suspected hilar lymph node metastases requiring radical hilar lymphadenectomy no longer represent a contraindication for laparoscopic approaches. Conventional minimally invasive laparoscopy might be switched to hand-assisted laparoscopy in complex cases to allow safe and radical lymphadenectomy in experienced hands. Furthermore, the laparoscopic approach is beneficial for staged or multimodal surgical strategies for addressing stage IV CRC (e.g. simultaneous primary resection and atypical liver resection or intraoperative local ablative techniques).

\section{Conclusion}

A multimodal approach to oligometastatic disease in CRC is mandatory for optimal patient treatment, especially with regard to staged liver approaches. Patients with stable disease after induction chemotherapy should not be denied hepatic resection. Surgical strategies should be strongly defined with regard to an adequate liver remnant. All patients with synchronous CRLM should be evaluated by a multidisciplinary team.

\section{Disclosure Statement}

The authors declare no conflict of interest. 


\section{References}

1 Van Cutsem E, Cervantes A, Nordlinger B, Arnold D; ESMO Guidelines Working Group: Metastatic colorectal cancer: ESMO Clinical Practice Guidelines for diagnosis, treatment and follow-up. Ann Oncol 2014; 25(suppl 3):iiil-9.

2 Adam R, de Gramont A, Figueras J, Kokudo N, Kunstlinger F, Loyer E, Poston G, Rougier P, RubbiaBrandt L, Sobrero A, Teh C, Tejpar S, Van Cutsem E, Vauthey JN, Pahlman L; of the EGOSLIM (Expert Group on OncoSurgery management of LIver Metastases) group: Managing synchronous liver metastases from colorectal cancer: a multidisciplinary international consensus. Cancer Treat Rev 2015;41:729-741.

3 Leitlinienprogramm Onkologie (Deutsche Krebsgesellschaft DK, AWMF): S3-Leitlinie Kolorektales Karzinom. 2014; Langversion 1.1, 2014, AWMF Registrierungsnummer: 021-007OL.

4 Ferrero A, Langella S, Russolillo N, Vigano L, Lo Tesoriere R, Capussotti L: Intraoperative detection of disappearing colorectal liver metastases as a predictor of residual disease. J Gastrointest Surg 2012;16:806-814.

5 Kuhlmann K, van Hilst J, Fisher S, Poston G: Management of disappearing colorectal liver metastases. Eur J Surg Oncol 2016;42:1798-1805.

6 Brudvik KW, Kopetz SE, Li L, Conrad C, Aloia TA, Vauthey JN: Meta-analysis of KRAS mutations and survival after resection of colorectal liver metastases. Br J Surg 2015;102:1175-1183.

7 Rees M, Tekkis PP, Welsh FK, O'Rourke T, John TG: Evaluation of long-term survival after hepatic resection for metastatic colorectal cancer: a multifactorial model of 929 patients. Ann Surg 2008;247:125-135.

8 Jonas S, Thelen A, Benckert C, Spinelli A, Sammain S, Neumann U, Rudolph B, Neuhaus P: Extended resections of liver metastases from colorectal cancer. World J Surg 2007;31:511-521.

9 Folprecht G, Gruenberger T, Bechstein WO, Raab HR, Lordick F, Hartmann JT, Lang H, Frilling A, Stoehlmacher J, Weitz J, Konopke R, Stroszczynski C, Liersch T, Ockert D, Herrmann T, Goekkurt E, Parisi F, Kohne $\mathrm{CH}$ : Tumour response and secondary resectability of colorectal liver metastases following neoadjuvant chemotherapy with cetuximab: the CELIM randomised phase 2 trial. Lancet Oncol 2010;11:38-47.

10 De Jong MC, Pulitano C, Ribero D, Strub J, Mentha G, Schulick RD, Choti MA, Aldrighetti L, Capussotti L, Pawlik TM: Rates and patterns of recurrence following curative intent surgery for colorectal liver metastasis: an international multi-institutional analysis of 1,669 patients. Ann Surg 2009;250:440-448.

11 Fong Y, Fortner J, Sun RL, Brennan MF, Blumgart LH Clinical score for predicting recurrence after hepatic resection for metastatic colorectal cancer: analysis of 1,001 consecutive cases. Ann Surg 1999;230:309-318; discussion 318-321.

12 Nordlinger B, Guiguet M, Vaillant JC, Balladur P, Boudjema K, Bachellier P, Jaeck D: Surgical resection of colorectal carcinoma metastases to the liver. A prognostic scoring system to improve case selection, based on 1,568 patients. Association Francaise de Chirurgie. Cancer 1996;77:1254-1262.
13 Sorbye H, Mauer M, Gruenberger T, Glimelius B, Poston GJ, Schlag PM, Rougier P, Bechstein WO, Primrose JN, Walpole ET, Finch-Jones M, Jaeck D, Mirza D, Parks RW, Collette L, Van Cutsem E, Scheithauer W, Lutz MP, Nordlinger B; EORTC Gastro-Intestinal Tract Cancer Group, Cancer Research UK (CRUK), Arbeitsgruppe Lebermetastasen und -tumoren in der Chirurgischen Arbeitsgemeinschaft Onkologie (ALM$\mathrm{CAO}$ ), Australasian Gastro-Intestinal Trials Group (AGITG), Fédération Francophone de Cancérologie Digestive (FFCD): Predictive factors for the benefit of perioperative FOLFOX for resectable liver metastasis in colorectal cancer patients (EORTC Intergroup Trial 40983). Ann Surg 2012;255:534-539.

14 Nordlinger B, Van Cutsem E, Gruenberger T, Glimelius B, Poston G, Rougier P, Sobrero A, Ychou M; European Colorectal Metastases Treatment Group, Sixth International Colorectal Liver Metastases Workshop: Combination of surgery and chemotherapy and the role of targeted agents in the treatment of patients with colorectal liver metastases: recommendations from an expert panel. Ann Oncol 2009;20:985-992.

15 Vauthey JN, Pawlik TM, Ribero D, Wu TT, Zorzi D, Hoff PM, Xiong HQ, Eng C, Lauwers GY, Mino-Kenudson M, Risio M, Muratore A, Capussotti L, Curley SA, Abdalla EK: Chemotherapy regimen predicts steatohepatitis and an increase in 90-day mortality after surgery for hepatic colorectal metastases. J Clin Oncol 2006;24:2065-2072.

16 Nordlinger B, Sorbye H, Glimelius B, Poston GJ, Schlag PM, Rougier P, Bechstein WO, Primrose JN, Walpole ET, Finch-Jones M, Jaeck D, Mirza D, Parks RW, Mauer M, Tanis E, Van Cutsem E, Scheithauer W, Gruenberger T; EORTC Gastro-Intestinal Tract Cancer Group; Cancer Research UK; Arbeitsgruppe Lebermetastasen und -tumoren in der Chirurgischen Arbeitsgemeinschaft Onkologie (ALM-CAO); Australasian Gastro-Intestinal Trials Group (AGITG); Fédération Francophone de Cancérologie Digestive (FFCD): Perioperative FOLFOX4 chemotherapy and surgery versus surgery alone for resectable liver metastases from colorectal cancer (EORTC 40983): longterm results of a randomised, controlled, phase 3 trial. Lancet Oncol 2013;14:1208-1215.

17 Stintzing S, Modest DP, Rossius L, et al.; FIRE-3 investigators: FOLFIRI plus cetuximab versus FOLFIRI plus bevacizumab for metastatic colorectal cancer (FIRE-3): a post-hoc analysis of tumour dynamics in the final RAS wild-type subgroup of this randomised open-label phase 3 trial. Lancet Oncol 2016;17:1426-1434.

18 Tejpar S, Stintzing S, Ciardiello F, Tabernero J, Van Cutsem E, Beier F, Esser R, Lenz HJ, Heinemann V: Prognostic and predictive relevance of primary tumor location in patients with RAS wild-type metastatic colorectal cancer: retrospective analyses of the CRYSTAL and FIRE-3 trials. JAMA Oncol 2016;DOI: 10.1001/ jamaoncol.2016.3797.

19 Vigano L, Capussotti L, Barroso E, Nuzzo G, Laurent C, Ijzermans JN, Gigot JF, Figueras J, Gruenberger T, Mirza DF, Elias D, Poston G, Letoublon C, Isoniemi H, Herrera J, Sousa FC, Pardo F, Lucidi V, Popescu I, Adam R: Progression while receiving preoperative chemotherapy should not be an absolute contraindication to liver resection for colorectal metastases. Ann Surg Oncol 2012;19:2786-2796.
20 Bischof DA, Clary BM, Maithel SK, Pawlik TM: Surgical management of disappearing colorectal liver metastases. Br J Surg 2013;100:1414-1420.

21 Van Vledder MG, de Jong MC, Pawlik TM, Schulick RD, Diaz LA, Choti MA: Disappearing colorectal liver metastases after chemotherapy: should we be concerned? J Gastrointest Surg 2010;14:1691-1700.

22 Zalinski S, Abdalla EK, Mahvash A, Vauthey JN: A marking technique for intraoperative localization of small liver metastases before systemic chemotherapy. Ann Surg Oncol 2009;16:1208-1211.

23 Abdalla EK, Vauthey JN, Ellis LM, Ellis V, Pollock R, Broglio KR, Hess K, Curley SA: Recurrence and outcomes following hepatic resection, radiofrequency ablation, and combined resection/ablation for colorectal liver metastases. Ann Surg 2004;239:818-825; discussion $825-827$.

24 Shiina S, Tateishi R, Arano T, Uchino K, Enooku K, Nakagawa H, Asaoka Y, Sato T, Masuzaki R, Kondo Y, Goto T, Yoshida H, Omata M, Koike K: Radiofrequency ablation for hepatocellular carcinoma: 10-year outcome and prognostic factors. Am J Gastroentero 2012;107:569-577; quiz 578

25 Allard MA, Adam R, Ruiz A, Vibert E, Paule B, Levi F, Sebagh M, Guettier C, Azoulay D, Castaing D: Is unexpected peritoneal carcinomatosis still a contraindication for resection of colorectal liver metastases? Combined resection of colorectal liver metastases with peritoneal deposits discovered intra-operatively. Eur J Surg Oncol 2013;39:981-987.

26 De Jong MC, van Dam RM, Maas M, Bemelmans MH Olde Damink SW, Beets GL, Dejong CH: The liverfirst approach for synchronous colorectal liver metastasis: a 5-year single-centre experience. HPB (Oxford) 2011;13:745-752.

27 Schadde E, Schnitzbauer AA, Tschuor C, Raptis DA, Bechstein WO, Clavien PA: Systematic review and meta-analysis of feasibility, safety, and efficacy of a novel procedure: associating liver partition and portal vein ligation for staged hepatectomy. Ann Surg Oncol 2015;22:3109-3120.

28 Stockmann M, Lock JF, Malinowski M, Niehues SM, Seehofer D, Neuhaus P: The LiMAx test: a new liver function test for predicting postoperative outcome in liver surgery. HPB (Oxford) 2010;12:139-146.

29 Bonjer HJ, Deijen CL, Abis GA, Cuesta MA, van der Pas MH, de Lange-de Klerk ES, Lacy AM, Bemelman WA, Andersson J, Angenete E, Rosenberg J, Fuerst A, Haglind E; Color II Study Group: A randomized trial of laparoscopic versus open surgery for rectal cancer. N Engl J Med 2015;372:1324-1332.

30 House MG: Laparoscopic resection for recurrent hepatic colorectal metastases. Ann Surg 2016;263:e73.

31 Tian ZQ, Su XF, Lin ZY, Wu MC, Wei LX, He J: Metaanalysis of laparoscopic versus open liver resection for colorectal liver metastases. Oncotarget 2016;7:8454484555 . 